\title{
Open Access Journal of Urology \& Nephrology
}

\section{Malone Procedure Combined with Mitrofanoff Using a Divided Appendix and Vesical Enlargement Description of the Surgical Technique and Case Report}

\section{José PP*, Justino LCC, Manuel GLGJ, Antonio VGM, Heriberto CS and Antonio GVR}

Pediatric Urology Department, Hospital of Pediatrics, Western Medical Center IMSS, Mexico

Urology Department of the General Hospital of the State of Sonora, Mexico

\section{Case Report \\ Volume 2 Issue 1}

Received Date: February 04, 2017

Published Date: March 06, 2017

*Corresponding author: Padilla Piña José, Urology Department of the General Hospital of the State of Sonora, Mexico, Tel: +526621903808; Email: drpadillajose@gmail.com

\begin{abstract}
Surgical treatment for neurogenic bladder has evolved notably. A great number of patients with neurogenic bladder also present fecal incontinence and treatment for these patients is discouraging. With the induction and use of the Malone procedure through appendicostomy, the practitioner may offer the confection of a stoma for cecal catheterization, allowing easy access for daily enemas. The objective of this report is to present one surgical technique, where the cecal appendix was divided on the proximal portion created a stoma for antegrade enema (Malone principle) and the distal portion created a stoma for urinary catheterization in an augmented bladder with an intestinal segment (Mitroffanoff principle).
\end{abstract}

Keywords: Neurogenic bladder; Mitrofanoff; Malone

\section{Introduction}

The function of the inferior urinary tract depends on the neuromuscular coordination of the bladder, the urethra and the striated muscle responsible for the sphincter mechanism. A neurological or muscular disorder in these structures causes dysfunction Void. The neurogenic bladder resulting from a neurological control disorder of continence and urination includes all problems of micturition whose origin is in the central nervous system [1]. The primary cause of dysfunctional neurogenic bladder in children is occult spina bifida; however, it may also be produced by sacral agenesis, tumors and inflammatory diseases affecting the spinal cord or spinal cord trauma [2]. It is essential to carry out urodynamic and imaging studies to determine the function of the high and low urinary tract in order to establish a treatment plan for each patient, and then to carry out an adequate follow-up. In the neurogenic bladder the urodynamic findings basically determine: detrusor over activity, detrusor sphinter dyssynergia and bladder with reduced bladder sensation [3]. The management of children with neurogenic bladders must be comprehensive, multidisciplinary and has three main objectives: Preserve renal function, seek urinary and fecal continence, and ensure that the patient becomes a self- 


\section{Open Access Journal of Urology \& Nephrology}

sufficient and useful person in society [4]. The treatment seeks to ensure that the patient reaches urinary continence and that the upper urinary tract remains protected from the progressive alterations that occur as a result of increased pressures in the lower urinary tract. To achieve this, interventions must be performed to convert a bladder of low capacity and / or high pressure into a reservoir with adequate capacity at a low pressure, allowing an easy and complete evacuation as well and hypotonic sphincter in a competent mechanism that does not allow the involuntary exit of urine. The ability to spontaneously urinate through the urethra should also be preserved, which is more difficult to achieve. Management of the neurogenic bladder should begin as soon as the diagnosis is made in order to prevent progressive deterioration of the upper urinary tract. The usual surgical procedures are: bladder augmentation, continual urinary stomas, including Mitrofanoff (cecal appendix reimplanted from the bladder to the abdominal wall) and the Monti tube (tubularization of a segment of the intestine and artificial sphincters, as well as urethral sling, submucosal injection of the bladder neck, reconstruction of the bladder neck and urethral cerclage to improve continence [5]. Surgical treatment can be complemented with pharmacological therapy, which consists of the administration of anticholinergic drugs that produce detrusor relaxation. The majority of patients with neurogenic bladder present alterations in colonic and anorectal function that cause fecal incontinence. Therefore, in some patients, procedures are performed to allow antegrade enemas, such as the Malone technique [6]. The main complication that occurs with the stoma is the stenosis for which different techniques have been designed that use flaps to avoid it or to correct it.

\section{Case Report}

We present a 14-year-old first born male patient, with history of complicated prenatal control characterized by multitreated recurrent urinary tract infections, term pregnancy, and at birth diagnosis of myelomeningocele and Arnold Chiari type II malformation. He was corrected for myelomeningocele and peritoneal ventricle bypass. In treatment from birth by orthopedics by bilateral equinovaro foot. An open reduction of hip joint was performed, as well as surgery of the medullary cone by ulceration of the filum terminale. Patient with neurogenic bladder that had been managed as a medium-risk bladder with clean intermittent catheterization, antibiotic prophylaxis and anticholinergic, begins its urological evaluation by our service with the following complementary studies: bilateral renal US in which bilateral hydro nephrosis is seen being more Important on the right side with a grade III/IV hydro nephrosis (International Reflux Study Committee) (Figure 1). The left side with grade I hydro nephrosis (Figure 2).

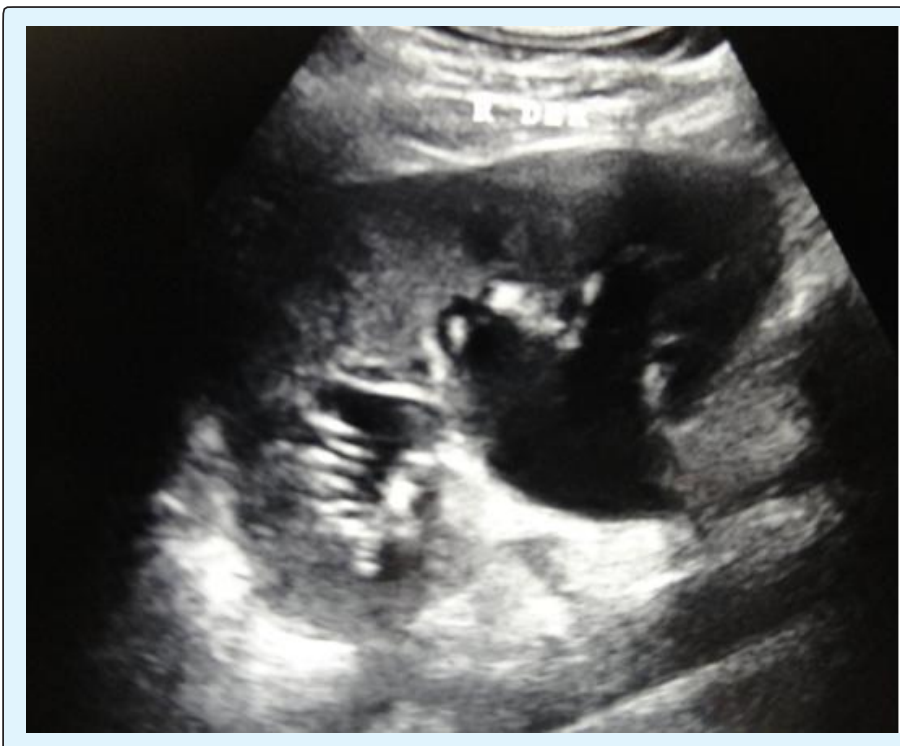

Figure 1: US Right renal with grade III hydronephrosis.

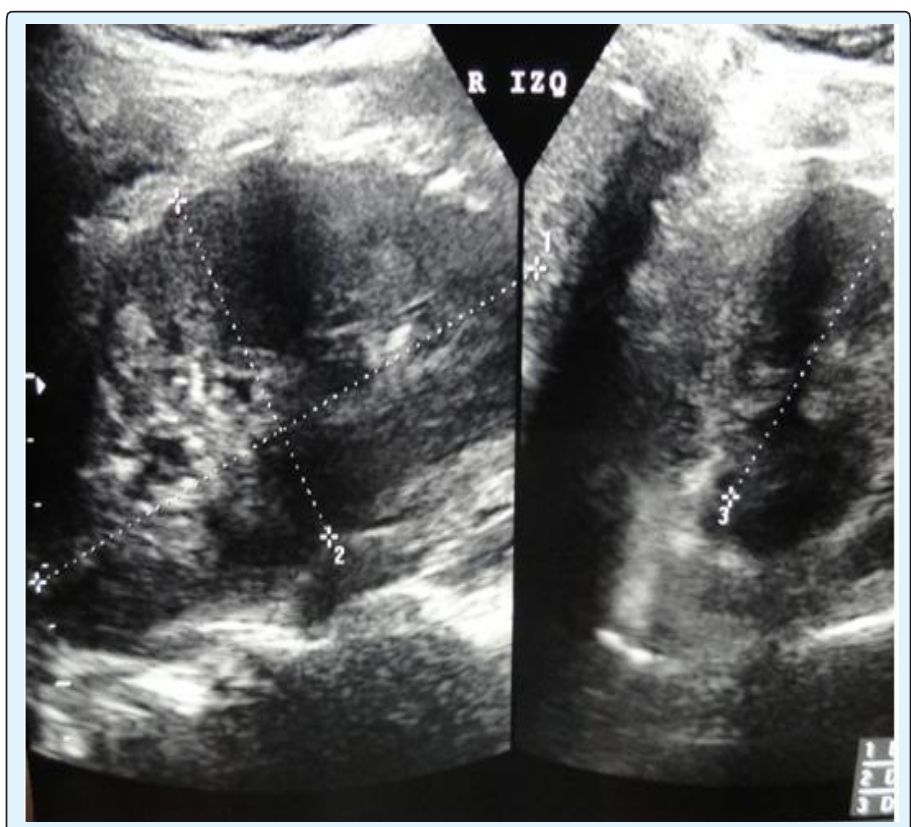

Figure 2: Left renal ultrasound where mild ectasia is seen.

When documenting hydronephrosis, we determined to perform a voiding urethrocistogram (Figure 3) in which we observed the classic bladder in a Christmas tree, with irregular walls, with diverticular formations and absence of vesicoureteral reflux. 


\section{Open Access Journal of Urology \& Nephrology}

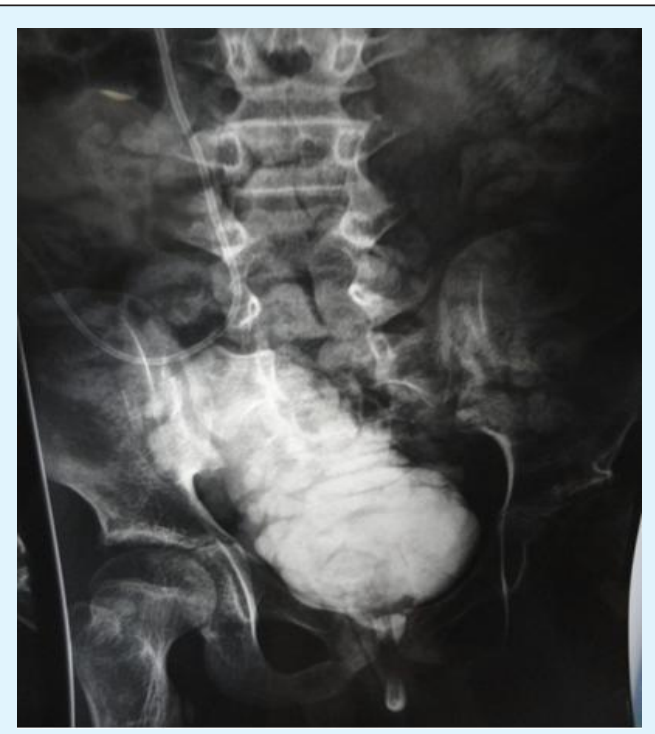

Figure 3: Urethrocytogram.

It complements the assessment with a urodynamic study (Figure 4) which reflects a decreased bladder capacity of $140 \mathrm{ml}$ (29\%), without unconstrained contractions, with a leakage point of $107 \mathrm{ml}$. Bladder with pressure increase up to $60 \mathrm{cmH}_{2} \mathrm{O}$ with decreased compliance, an accommodation of $5 \mathrm{ml} / \mathrm{cm} . \mathrm{sup} .20$ and an average filling pressure of $38 \mathrm{~cm} \mathrm{H}_{2} \mathrm{O}$.

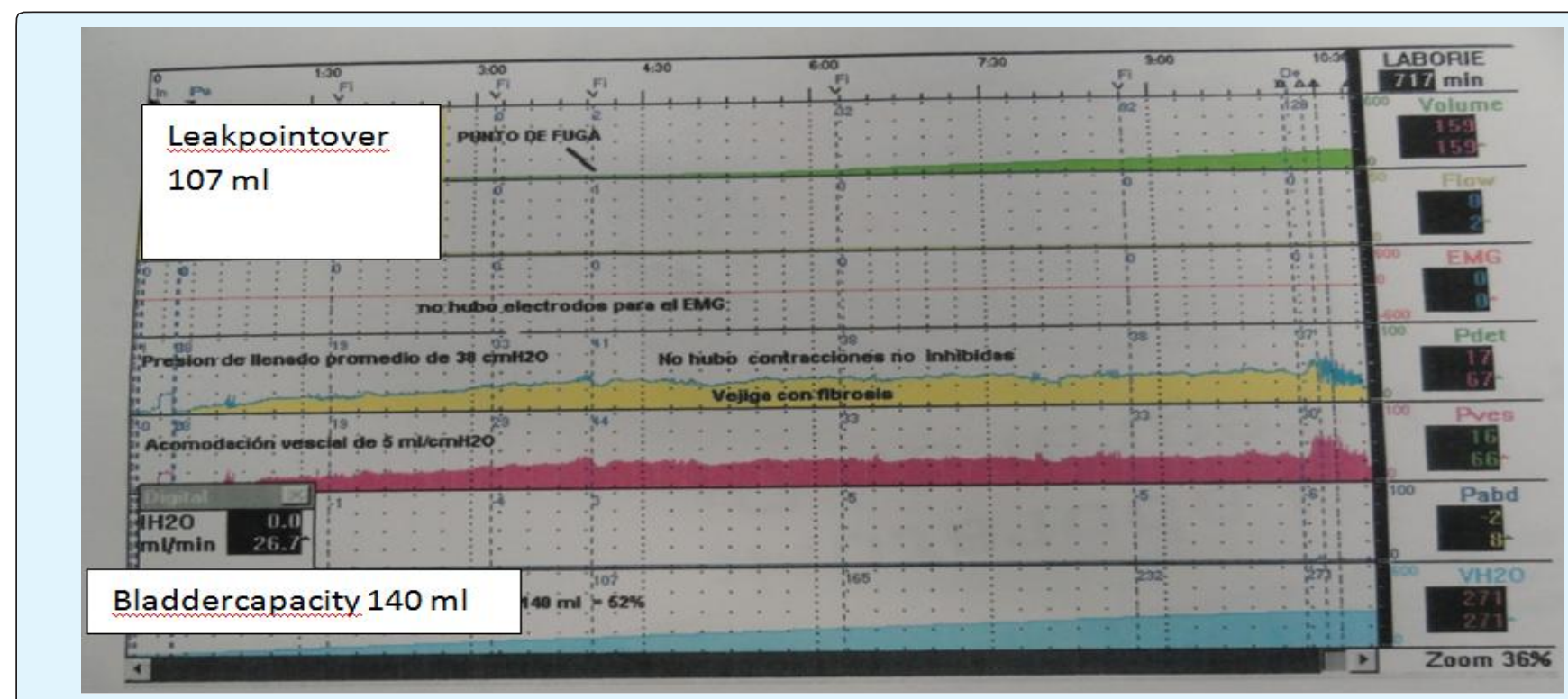

Figure 4: Urodynamic study showing a neurogenic bladder.

With the results of the studies already mentioned, it is possible to catalog as a high-risk bladder, thus being a candidate for bladder enlargement with continent catheterization. He is offered to perform at the same time the procedure of Malone, due to the antecedent of constipation present in this case.
Preoperative laboratory studies were performed obtaining Hb 13.2 Hto. 36.2 Platelets 320000 TP 13.1 TPT 30.3 Creatinine 0.9 .

The surgical technique that was developed was the following: an umbilical mid incision was made, the 


\section{Open Access Journal of Urology \& Nephrology}

abdominal cavity was entered and the bladder was separated from the abdominal cavity; Approximately 15 $\mathrm{cm}$ of colonic segment was taken, resection was performed with whole-integer anastomosis in two coloncolonic planes and bladder enlargement was performed with this segment with meso (Figure 5). The appendix was removed, which was approximately $15 \mathrm{~cm}$ in length (Figure 6).

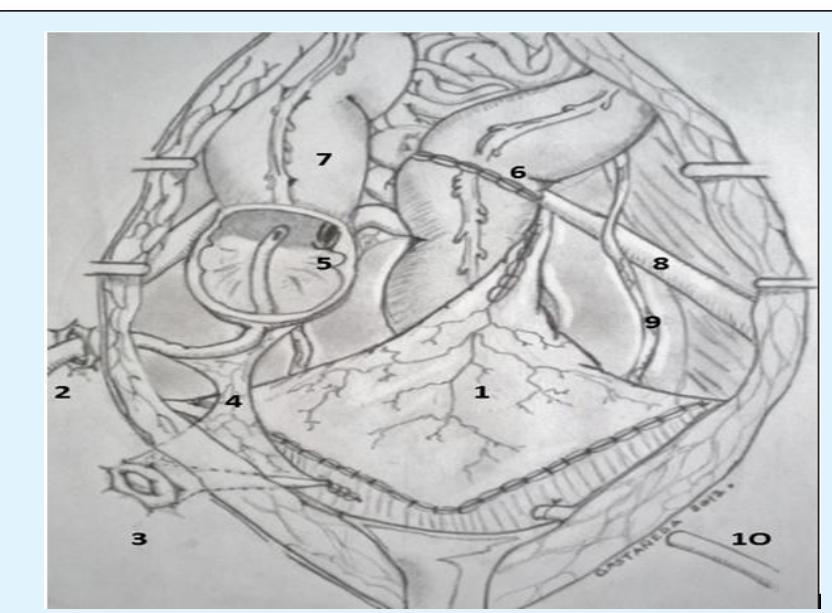

Figure 5: Illustration of colono-colonic anastomosis and appendectomy performed.
1. Sigmoidocystoplasty
2. Malone stoma with catheter
3. Mitrofanoff stomata
4. Mesoappendix
5. Ileocecal valve
6. End-to-end intestinal anastomosis
7. Ascending colon
8. Iliac Cup
9. Left ureter
10. Cystostomy

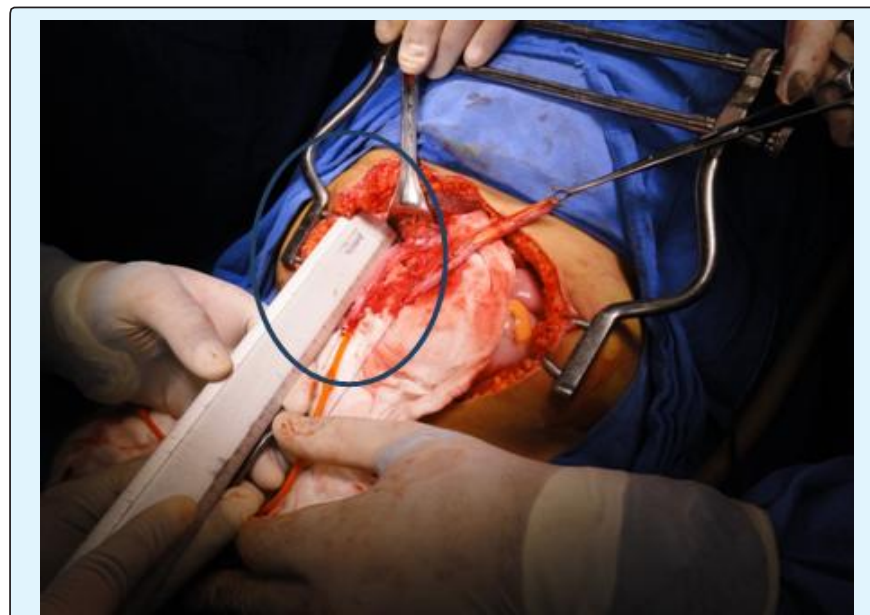

Figure 6: Photo showing the appendicular size to be used for the catheterized ducts $15 \mathrm{~cm}$.
The mesoapendice was divided, half of the appendix was used to perform the procedure of Malone that went towards the right iliac fossa; the other segment of the appendix went to the umbilical scar and the Mitrofanoff was made into the bladder (Figure 7).

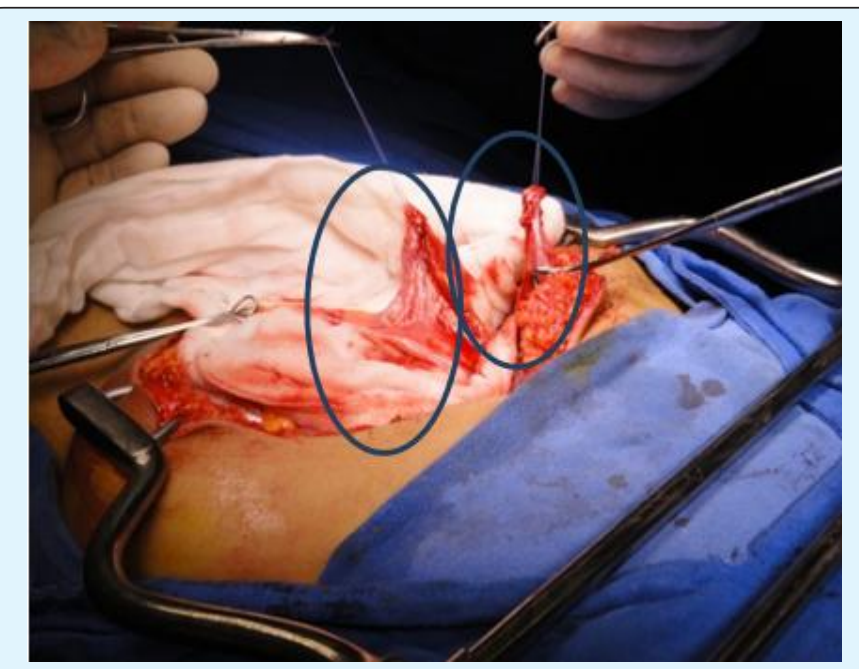

Figure 7: Photo showing the separate appendix, one part was used for the Mitrofanoff and the other segment for the Malone.

The final results of the surgical procedure were: 100 $\mathrm{mL}$ bleeding, surgical time 210 minutes, 14-day inhospital stay.

The patient was exited with silicon probes by mitrofanoff stents (Figure 8) and functional Malone, the drains were removed until the expenditure was less than $50 \mathrm{ml}$ and the probes were removed at 21 postoperative days.

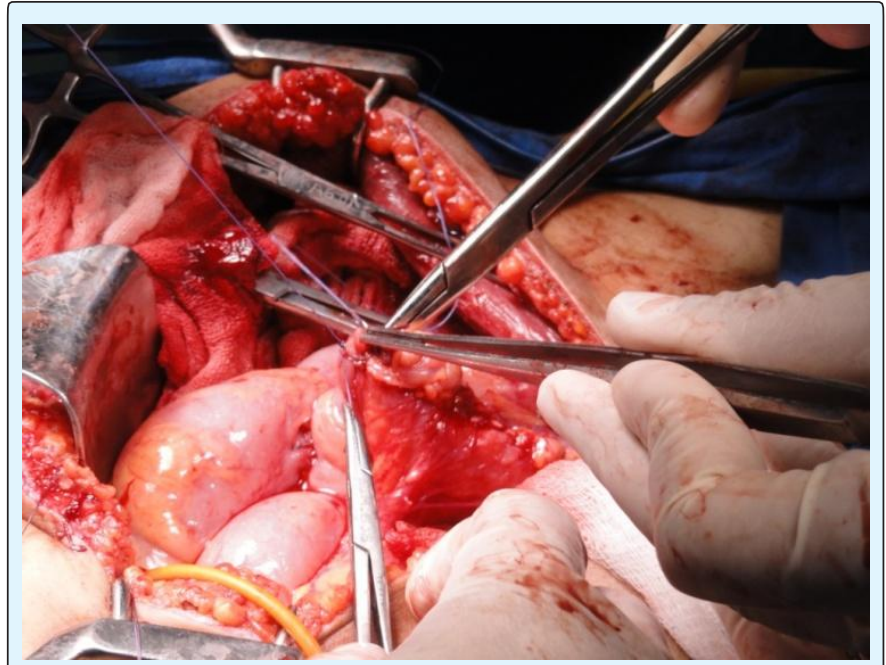

Figure 8: Making the final mitrofanoff bag. 


\section{Open Access Journal of Urology \& Nephrology}

\section{Discussion}

The final outcome of the Mitrofanoff technique can be evaluated in terms of urinary continence, absence of complications of the stoma, surgical reinterventions due to complications and protection of the upper urinary tract. In general, it can be said that the results regarding continence are good, although in the series with longer follow-up there is a high frequency of surgical examinations of the duct, by filtration and stenosis according to what was published by Arango et al. in 2009 (7).

In 1990 Malone et al first described the continent-wide anterograde enema (EAC) technique for the treatment of severe fecal incontinence of neurogenic origin in children and has subsequently been successfully used also in adults and in patients with constipation who do not respond to medical treatment. The procedure consists of the formation of a continent duct, generally an appendectomy that allows intermittent catheterization for irrigation and the rapid and controlled cleaning of the colon described by Elsenberg in 2012 (8). This technique combines the principles of anterograde lavage of the colon and the catheterizableanti reflux duct described by Mitrofanoff for the treatment of the neurogenic bladder. The goal is to achieve a complete cleaning of the colon to prevent fecal impaction and to avoid the episodes of incontinence described by Monti in 2008 (9). In the original description, the appendix was sectioned at its base and vascularization was preserved. From the moment this principle was exposed, the appendix was constituted as the tissue of choice for the development of the duct; in this case the Malone surgery was performed to improve fecal continence with periodic lavage through the continent stoma. The choice of the type of canal to be used depends on several factors including availability, type of surgery and basic diagnosis according to Landero et al in 2009 (10). The defect in the cecal wall was closed and the appendix $180^{\circ}$ was rotated, with reimplantation in one of the blind's tapeworms through a $5 \mathrm{~cm}$ long submucosal tunnel to avoid the reflux described by Landero and Gladman in 2008 and $2009(10,11)$. Modifications of the original technique have been described in recent years, which in some cases simplify the procedure. In our patient, the surgical techniques of Mitrofanoff and Malone were performed, with a long cecal appendix of $15 \mathrm{~cm}$, divided into two segments, as reported by Kajbafzadeh M. et al in 2001 being the first report in the literature. (12). they concluded that the appendix greater than $9 \mathrm{~cm}$ is ideal to develop this surgical technique in conjunction with V-flap technique for the stoma and to reduce its main complication than stoma stenosis.

\section{Conclusion}

The technique of Malone should be taken into account in patients with severe constipation and fecal impaction, since it facilitates regular colon cleansing and reduces encopresis, which significantly limits the quality of life of the patient.

Successful treatment of urinary and fecal incontinence secondary to neuropathic disorders can improve the quality of life of children, achieving greater socialization and well-being. The development of the catheterisablevesicocutaneous duct technique described by Mitrofanoff has been the main contribution in achieving adequate control of urinary continence and has been of great importance for periodic bladder emptying.

The management of the neurogenic bladder requires a complete assessment of the patient's conditions, basic diagnosis and associated pathologies; this will depend on the prognosis of our patients.

Surgical treatment of the bladder with neurogenic bladder prevents renal damage and generates advantages in terms of continence, comfort and quality of life.

\section{References}

1. Malone PS, Ransley PG, Kiely EM (1990) Preliminary report: the antegrade continence enema. Lancet 336(8725): 1217-1218.

2. Bica D (1996) Apendicecostomiaortotopica continente 5 casos. Rev de Cir Infantil (6): 4.

3. Orabi A, Paterson HM, Goncette L, Danse E, Saey JP, et al. (2011) Malone appendicostomy: an unexpected complication. Tech Coloproctol 15(1): 81-83.

4. Esteves E, Pereira R, salgado C, Neto M, Pena H (1999) Tratamiento quirúrgico simultaneo de la vejiga neurogénica y la incontinencia fecal en niños. Rev de Cir Infantil 9(2): 88-93.

5. Traxel E, Minevich EA, Noh PH (2010) A review: The Application of Minimally Invasive Surgery to Pediatric urology: lower urinary tract reconstructive procedures. Urology 76(1): 115-120.

6. Pera M, David Parésa, Marta Pascuala, Marta Pereza, Nuria Cañeteet, et al. (2006)Tratamiento del estreñimiento crónico grave mediante la técnica del enema anterógrado continente. Cir Esp 80(6): 403405. 


\section{Open Access Journal of Urology \& Nephrology}

7. Arango M, Luis F Lince Varela, Catalina Salazar Sanín, Francisco C Hoyos Figueroa, Sara N Hurtado, et al. (2009) Resultados del uso de la técnica de Mitrofanoff en pacientes con disfunción neurógena de la vejiga: Análisis de la experiencia en el Hospital Universitario San Vicente de Paul. Actas Urol Esp 33(1): 69-75.

8. Elsenberg E, Johnson J, Santucci R (2012) Pilot Study of the Vesicocutaneous Continent Catheterizable Stoma (Mitrofanoff) in Adults-High Complication Rates. Urology 79(1): 222-226.

9. Cain M, Dussinger AM, Gitlin J, Casale AJ, Kaefer M, el al. (2008) Updated Experience With the Monti Catheterizable Channel. Urology 72(4): 782-785.
10. Landero OM, León-Gómez JM GD (2009) Técnica de Malone para el enema anterógrado continente en niños con afección neurógena intestinal y urinaria. Rev Mex Urol 69(6): 268-272.

11. Gladman M, Knowles CH (2008) Surgical Treatment of Patients with Constipation and Fecal Incontinence. Gastroenterol Clin North Am 37(3): 605-625.

12. Kajbafzadeh M, Chubak N (2001) Simoultaneous Malone anterograde continent enema and Mitrofanoff principle using dividen appendix: Report of a new technique for prevention of stoma complication. J Urol 165(6): 2404-2409. 